\title{
Tumor Graft
}

National Cancer Institute

\section{Source}

National Cancer Institute. Tumor Graft. NCI Thesaurus. Code C122941.

The transfer of a tumor fragment into an ectopic or orthotopic site, within the same individual or between individuals. 